\title{
Ecological analyses of the intestinal helminth communities of the wolf, Canis lupus, in Spain
}

\author{
Juan-Matías Segovia ${ }^{1}$, Ricardo Guerrero $^{2}$, Jordi Torres $^{1}$, Jordi Miquel $^{1}$ and Carlos Feliu $^{1}$ \\ ${ }^{1}$ Laboratori de Parasitologia, Departament de Microbiologia i Parasitologia Sanitàries, Facultat de Farmàcia, Universitat de \\ Barcelona, Avda. Joan XVIII s/n, E-08028 Barcelona, Spain; \\ ${ }^{2}$ Instituto de Zoología Tropical, Facultad de Ciencias, Universidad Central de Venezuela. P.D. Box 47058, Caracas 1041A, \\ Venezuela
}

Key words: helminths, communities, Canis lupus, Spain

\begin{abstract}
This work describes the ecological characteristics of the intestinal helminth communities of 50 wolves (Canis lupus L.) from Spain. The species found were classified into three groups according to prevalence, intensity and intestinal distribution. Taenia hydatigena Pallas, 1766 and Uncinaria stenocephala (Railliet, 1884) are the core species of the community. Taenia multiceps (Leske, 1780) is a secondary species. The rest of the species, Alaria alata (Goeze, 1782), Taenia serialis (Gervais, 1847), Taenia pisiformis (Bloch, 1780), Dipylidium caninum (Linnaeus, 1758), Mesocestoides sp. aff. litteratus, Toxocara canis (Werner, 1782), Toxascaris leonina (von Linstow, 1902), Ancylostoma caninum (Ercolani, 1859) and Trichuris vulpis (Froelich, 1789), behave as satellite species. The linear intestinal distribution of all helminth species was analysed. The location of most species can be considered predictable, especially for core and secondary species. The analysis of interspecific relationships between infracommunities shows that negative associations are more numerous than positive associations. The role of $A$. caninum in the community is compared with that of U. stenocephala.
\end{abstract}

The ecological research aimed at characterising the structure and populational dynamics of intestinal helminth communities in carnivores is scarce and has only been carried out in the New World. Significant studies include those of Pence et al. (1980) in bobcats, Custer and Pence (1981) in wolves and coyotes, Pence et al. (1983) in black bears, Pence et al. (1984) in coyotes and more recently, Iannacone et al. (2001) in stray dogs.

The wolf (Canis lupus L.) is a canid whose Spanish distribution is limited to two populations located in distinct biogeographical regions (Blanco et al. 1992). The main unfragmented population lives in the northwest of Spain and its lower limit seems to be the Duero River. The second population consists of scattered groups, with a tendency to decrease in size, that inhabit the southwest of Spain. The wolf is currently classified as a protected species throughout most of the Iberian Peninsula. It is, therefore, difficult to obtain large samples for parasitological studies. However, a recent study carried out on a sample of 47 wolves (Segovia et al. 2001) revealed that 1 trematode, 5 cestodes and 5 nematodes constitute the intestinal helminth communities of Spanish wolves. These data have provided the basis for a broader study allowing the evaluation of possible interactions between the species that share the microhabitat and the influence of these species, according to Holmes (1973), on the structure of worm communities.
The current study, the first of its kind in Europe carried out on a carnivore, aims to determine the structural characteristics of the intestinal helminth infracommunities of the wolf, and to analyse some of the factors that can influence them.

\section{MATERIALS AND METHODS}

All wolves, coming from various localities, were part of an unfragmented population that inhabits the northwest of Spain. The 50 specimens studied were provided by official institutions between 1993 and 2001. The intestinal tracts of the wolves arrived at our laboratory in a frozen state. Once defrosted to room temperature, each intestinal tract was cut into 20 portions. The first eighteen, all of the same length, were obtained starting from the small intestine, while the two remaining portions consisted of the caecum and the large intestine. A $90 \%$ of intestinal length (5\% per portion) was assigned to the 18 sections of small intestine, while $10 \%$ was assigned to the last two tracts (caecum and large intestine). The content of each section was examined separately, and the helminths extracted were identified on the basis of previous descriptions (Segovia et al. 2001).

Some parameters such as prevalence, range of intensity, mean intensity, abundance, range of intestinal distribution, mean distribution and location of maximum intensity, were determined for each of the helminth species. The use of descriptive ecological terms follows Bush et al. (1997). The coefficient of dispersion $\left(\mathrm{s}^{2} /\right.$ mean) was calculated using data of mean intensity and variance for the helminth species. The

Address for correspondence: J.-M. Segovia, Laboratori de Parasitologia, Departament de Microbiologia i Parasitologia Sanitàries, Facultat de Farmàcia, Universitat de Barcelona, Avda. Joan XVIII s/n, E-08028 Barcelona, Spain. Phone: ++34 934 024 500; Fax: ++34 934 024 504; E-mail: jmsegovia@ub.edu 
data of location for each helminth species was transformed from a discrete variable (section number) to a continuous variable (percentage of intestinal length from the pylorus) following Bush and Holmes (1986b). The location of the cestodes was established according to the position of the scolex. The fundamental distribution, analogous to the fundamental niche of Hutchinson (1957), at least in its linear aspects, was determined for each of the three most prevalent species, starting with individuals parasitized by a single species.

Some statistical tests (non-parametrics wherever possible), e.g. Spearman rank correlation and Kendall's Tau, were used to evaluate the statistical significance of the results obtained. Regular co-occurrences were tested against co-occurrences by chance by means of chi-square test (considering the product of prevalence as probability of co-occurrence by chance). The affinity index of Fager and McGowan (1963) was also calculated. The interspecific associations and their role in the organisation of the intestinal helminth communities were evaluated by a pairwise analysis of covariance of presence/ absence data (Schluter 1984, Lotz and Font 1991, Lotz and Font 1994). SPSS for Windows was used to calculate the descriptive and inferential tests. Significance was taken at $p<$ 0.05 unless otherwise specified.

\section{RESULTS}

A total of 1724 individuals of 12 intestinal helminth species were found: the trematode Alaria alata (Goeze, 1782), the cestodes Taenia hydatigena Pallas, 1766, T. multiceps (Leske, 1780), T. serialis (Gervais, 1847), T. pisiformis (Bloch, 1780), Dipylidium caninum (Linnaeus, 1758) and Mesocestoides sp. aff. litteratus, and the nematodes Toxocara canis (Werner, 1782), Toxascaris leonina (von Linstow, 1902), Uncinaria stenocephala (Railliet, 1884), Ancylostoma caninum (Ercolani, 1859) and Trichuris vulpis (Froelich, 1789). Each wolf was parasitized by a mean of 2 species (Range $=0-5$, Variance $=1.2$ ) and 34 individuals (Range $=0-480, \mathrm{SD}=72.5$ ). The prevalence, abundance and coefficient of dispersion $\left(\mathrm{s}^{2} /\right.$ mean) values corresponding to each species are shown in Table 1. In the majority of cases the coefficient of dispersion showed a pattern of aggregated distribution $\left(\mathrm{s}^{2}>\right.$ mean), ranging between 1 and 320.6.

\section{Helminth patterns}

The representation of number of species versus frequency provides a trimodal graph (Fig. 1), which indicates that the community consists of three groups of species. The identification of these groups as "core", "secondary" and "satellite species" was based, as in Bush and Holmes (1986a), on the application of Caswell's and Hanski's dichotomy (Caswell 1978, Hanski 1982, 1991) using prevalence to represent regional dispersion and intensity to represent abundance. There was a positive correlation (Spearman rank correlation, $\mathrm{r}=0.685, \mathrm{p}<0.01$ ) between frequency and intensity. Core species were few (2 of 12 species) and abundant. Their prevalence is upwards of $50 \%$ and

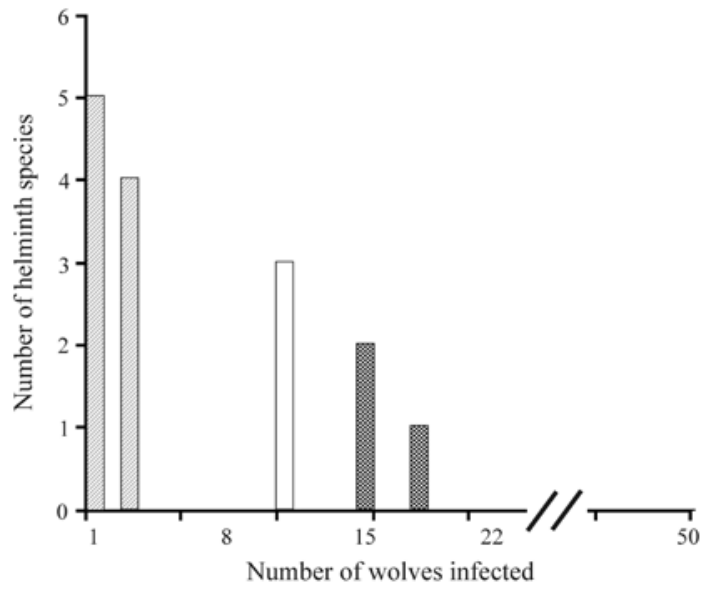

Fig. 1. Frequencies of intestinal helminth species in wolves from Spain $(n=50)$.

represented on the right hand side of the graph. Secondary species harbour only $T$. multiceps, with prevalence between core and satellite species. Both core and secondary species are canid specialist. The third group (satellite species) is represented on the left hand side of the graph, and includes species that have been found sporadically (prevalence $\leq 10 \%$ ), constituting the largest group.

Taenia hydatigena and U. stenocephala are considered core species (which represent $63.9 \%$ of all individual helminths found), T. multiceps secondary species $(17.7 \%)$ and the rest $(18.4 \%)$ satellite species. Seven of the twelve species $(58.3 \%)$ found are canid specialists: A. alata, T. hydatigena, T. serialis, T. multiceps, $A$. caninum, $U$. stenocephala and $T$. vulpis, while the rest are host generalists. Three specialist species (T. hydatigena, T. multiceps and U. stenocephala) showed the highest prevalence and intensity.

The examination of regular co-occurrences by the index of affinity of Fager and McGowan (1963) showed a value upwards of 0.5 in only one pair of species (Taenia hydatigena / Uncinaria stenocephala). By testing co-occurrences found against co-occurrences by chance, only the pairs made by core and secondary species among themselves gave significant differences ( $p<$ $0.05)$. The analysis of covariance on pairwise presence/ absence data revealed a predominance of negative covariances (86 negative and 46 positive). Taenia hydatigena and $U$. stenocephala showed the highest number of positive pairwise covariances with respect to the other species.

\section{Distribution patterns}

The linear distribution of each species is represented in the chart (Fig. 2). Collectively, all species occupied the entire intestine (Fig. 3), even though all sections showed a low level of occupancy (mostly upwards of $50 \%$ were unoccupied). The highest percentage of 
Table 1. General prevalence (P\%), abundance (A) \pm standard error of the mean (SEM), intensity ranges (IR) and coefficient of dispersion $\left(\mathrm{s}^{2} /\right.$ mean $)$ of helminth species parasitizing Canis lupus $(\mathrm{n}=50)$ in Spain.

\begin{tabular}{|l|c|c|c|c|}
\hline \multicolumn{1}{|c|}{ TREMATODA } & P \% & A \pm SEM & IR & s $^{2} / \mathrm{mean}$ \\
\hline Alaria alata & 2 & $0.02 \pm 0.02$ & 1 & 1.0 \\
\hline \multicolumn{1}{|c|}{ CESTODA } & & & & \\
Taenia hydatigena & 64 & $7.68 \pm 2.09$ & $1-59$ & 28.4 \\
Taenia multiceps & 28 & $6.10 \pm 2.44$ & $1-101$ & 48.7 \\
Taenia serialis & 8 & $2.12 \pm 1.33$ & $3-60$ & 41.5 \\
Taenia pisiformis & 4 & $0.70 \pm 0.49$ & $17-18$ & 17.2 \\
Dipylidium caninum & 6 & $0.14 \pm 0.09$ & $1-4$ & 2.9 \\
Mesocestoides sp. aff. litteratus & 4 & $2.70 \pm 2.28$ & $23-112$ & 96.1 \\
\hline \multicolumn{1}{|c|}{ NEMATODA } & & & & \\
Trichuris vulpis & 10 & $0.14 \pm 0.07$ & $1-3$ & 1.8 \\
Ancylostoma caninum & 8 & $0.20 \pm 0.11$ & $1-5$ & 3.3 \\
Uncinaria stenocephala & 52 & $14.36 \pm 9.60$ & $1-479$ & 320.6 \\
Toxocara canis & 6 & $0.20 \pm 0.15$ & $1-7$ & 5.3 \\
Toxascaris leonina & 4 & $0.12 \pm 0.09$ & $2-4$ & 3.3 \\
\hline
\end{tabular}

Table 2. Matrix of covariances based on presence/absence data. Positive pairwise covariances between species are shaded.

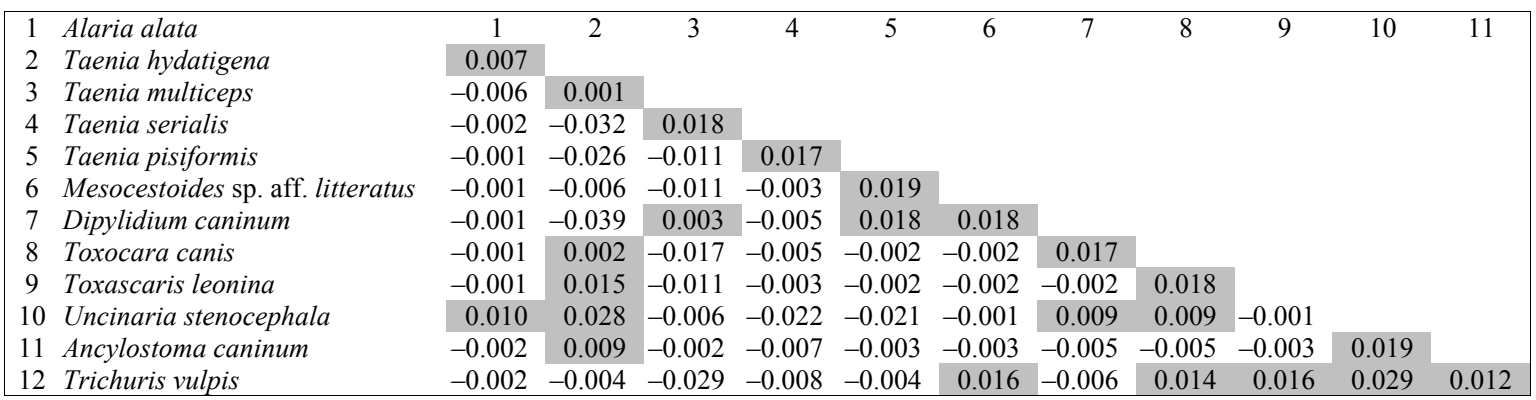

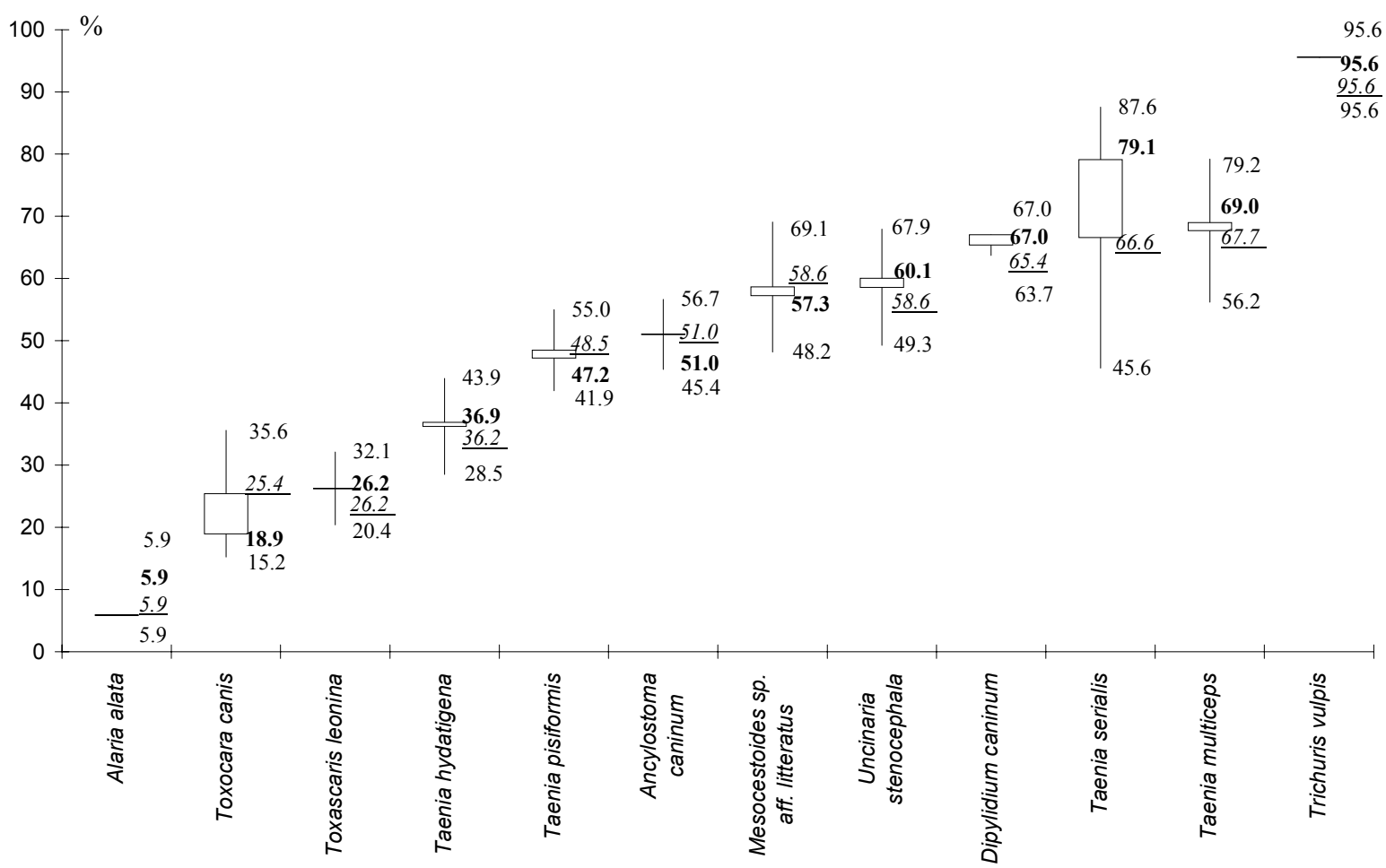

Fig. 2. Intraintestinal distributions of helminth species from Iberian wolves. All values (anterior and posterior) are given in percentage of intestinal length starting from the pylorus. The mean (in italic type and underlined) and the mode (in bold) for each species are also given in percentage of intestinal length. 


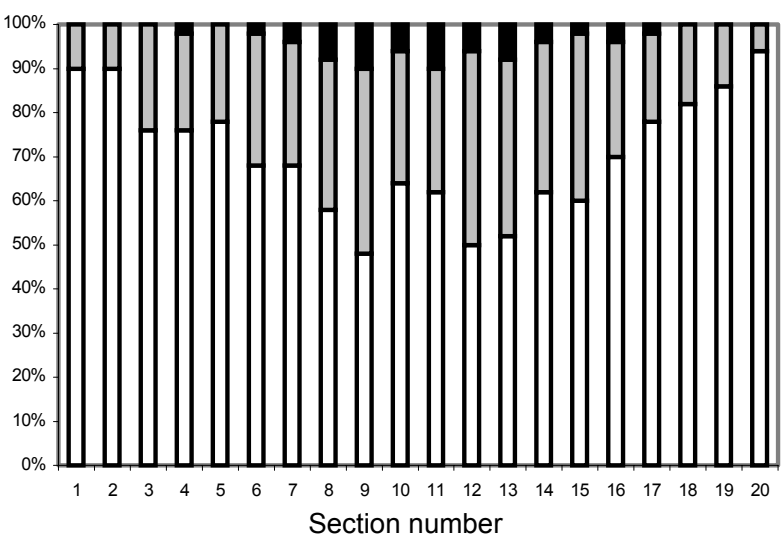

Fig. 3. Percentage of occupancy for helminth species in the intestinal sections of 50 Spanish wolves. $\square>1$ species, $\square$ single species only, $\square$ unoccupied.

occupation was found between sections 6 and 16, whereas the extremities only occasionally harboured some species such as the nematode $T$. vulpis, which was only found in the final $10 \%$ of the intestine (sections 19-20).

All core and secondary species showed a significant correlation $(\mathrm{p}<0.01)$ between population size and percentage of intestinal occupation. This correlation was also significant $(\mathrm{p}<0.01)$ in 3 of the 9 satellite species (Mesocestoides sp. aff. litteratus, T. leonina and $A$. caninum). However, the location of the median distribution across the intestine was not correlated with the population size, except in the case of the ascaridids T. canis, T. leonina and the cestode Mesocestoides sp. aff. litteratus.

The comparison of linear distribution of core and secondary species, when they were found alone, and with other species, did not reveal statistically significant differences. This might be due to the low number of wolves parasitized by a single species.

Upon examination of the occupancy of the intestine, two zones in the first intestinal third were differentiated. The first zone covers $0-15 \%$ of length (sections 1-3) and harboured a single helminth species, the trematode A. alata. The second zone covers $20-25 \%$ of length (sections 4-6) and corresponds to the portions normally occupied by the ascaridids $T$. canis and T. leonina. The two most prevalent taeniids, $T$. hydatigena and $T$. multiceps, presented a clear differential distribution without overlapping their ecological niches (Fig. 2). The intestinal distribution of $U$. stenocephala showed a range partially overlapped with $T$. multiceps (56.2$79.2 \%$ ) but located more anteriorly (49.3-67.9\%). The margins corresponding to the lower and upper limits of both majority taeniid species included the intestinal range in which the ecological niches of most species that constitute the community were located.

\section{DISCUSSION}

Spanish wolves present an intestinal helminth community consisting equally of generalist and specialist species. We found, as in Bush and Holmes (1986a), mostly significant co-occurrences between their own core species, and between core and secondary species.

In general, the helminth species are not randomly distributed along the intestine, and so their location can be considered predictable. Our results are similar to those obtained by Iannacone et al. (2001) on stray dogs Canis familiaris L. from Brazil in that the three helminth species found in Brazilian stray dogs were also found parasitizing Spanish wolves. However, in this study a similar prevalence was found for all of them. Distribution data agree with those of Iannacone et al. (2001) for Dipylidium caninum and Toxocara canis, although the ascarid shows a slightly more posterior distribution in Spanish wolves. This difference may be due to the presence in the community of the trematode Alaria alata, which always occupied the first intestinal section. Regarding Taenia pisiformis, the results seem to show a more specific localisation around the middle of the intestine, but the low prevalence found for this taeniid does not allow us to assert this.

Lotz and Font $(1991,1994)$ used the analysis of pairwise covariances to study interspecific interactions on helminth communities of bats. Our results show a higher number of negative than positive covariances (Table 2). Interpreting this fact under the competition theory, this indicates an excess of interspecific negative associations, in agreement with the high number of uncommon species found (Lotz and Font 1994).

\section{Core species}

A mean of two species was found in each wolf. The lack of similarity in these species (normally $T$. hydatigena and $U$. stenocephala) may indicate that their adaptation to the communities of wolves took place in distinct ways. The predominance of the core species seems to be determined as much by the type of diet as by the ethology of the wolf. Canis lupus is a top carnivore occupying a high level in the trophic chain. In northern Spain, it is the only carnivore that can hunt large animals like young horses and some large wild herbivores, which are the intermediate hosts of $T$. hydatigena. The analysis of recurrent groups shows that $T$. hydatigena is a regular species in the infracommunities of wolves. The matrix of covariances from pairwise presence/absence data shows that $T$. hydatigena is positively associated with six species of the community (Table 2). This was the highest number of positive pairwise covariances found, which was shared by the remaining core species.

Uncinaria stenocephala shows an ecological niche which fits well, almost centred, into the intestinal range located between $T$. hydatigena and T. multiceps. The distribution data of $U$. stenocephala and Ancylostoma caninum did not differ significantly, indicating a compe- 
tence for the ecological niche in the community. The higher prevalence and abundance of $U$. stenocephala is surprising, since $A$. caninum has a higher specificity regarding canids (Fitzsimmons 1961, Burrows 1962, Okoshi and Murata 1967, 1968). This feature has also been reported in other countries with a climate similar to that of Spain; e.g., Guberti et al. (1993) suggested antagonism between the two ancylostomatid species in wolves from Italy. The drastic reductions in wolf populations may explain the low prevalence of $A$. caninum, for which wolves may have been natural hosts for the last century. According to Stork and Lyal (1993), the fate of host specialists is usually inextricably linked to that of the host.

Both ancylostomatids have direct life cycles, and so cohabitation of the hosts is a key factor in their development. In the case of the wolf, the type of prey conditions the size of packs. When large herbivores are available, the packs contain about 10 to 20 individuals. Spanish wolves usually gather in packs of fewer than 10 individuals because they are forced to consume smaller prey (Blanco et al. 1992). The above findings suggest that, in the ancestral helminth configuration of the communities of wolves, the ancylostomatid A. caninum could have played an important role. The reductions in wolf populations and the forced diet adaptations may have hindered the development of the biological cycle of $A$. caninum, while favouring the prevalence of $U$. stenocephala, whose larvae and eggs are more resistant in the external environment (Gibbs and Gibbs 1959, Balasingam 1964). The behaviour of the other Iberian wild canid, Vulpes vulpes L., differs in that its social groups are smaller, which in our opinion limits the full substitution of the wolf as a definitive host of $A$. caninum. Although more studies have been devoted to the fox than the wolf in Spain, there are very few reports on A. caninum in this canid. In this regard, Miquel (1993) found only two females of A. caninum in 2 of the 132 Spanish foxes examined.

\section{Secondary species}

Taenia multiceps was the only secondary species considered. Its prevalence (28\%) was markedly high, but not high enough to classify it as a core species. However, the analysis of co-occurrences revealed the relevance of this species in the community, since its presence is significantly associated with that of core species.

The role of $T$. multiceps in the community may be influenced, as in the case of T. hydatigena, by the diet of the wolf, since several intermediate hosts are common to both taeniids, such as sheep, goats and cows. Its adaptation to the wolf has been documented elsewhere: in Italy, Guberti et al. (1993) reported for T. multiceps an independent wild cycle between wolves and large herbivores, indicating the ability of $T$. multiceps to adapt to the wolf as definitive host.
The analysis of distribution data indicates that the location of $T$. multiceps along the intestine is independent of the intensity and can be considered predictable. Comparison with $T$. serialis showed a positive association starting from presence/absence data, although the two species seem to compete for the ecological niche, since their intestinal locations did not differ significantly.

\section{Satellite species}

Nine species were regarded as satellite species. Although they constitute the largest group, few individuals are usually provided to the intestinal helminth infracommunities of wolves. The only exception is Mesocestoides sp. aff. litteratus, whose high intensities influence (Kendall's Tau $=1, \mathrm{p}<0.01$ ) the individual median distributions of Dipylidium canium, T. hydatigena, $U$. stenocephala and T. leonina.

A positive pairwise covariance was found in Taenia pisiformis and $T$. serialis, two species that use lagomorphs as intermediate hosts. Their low prevalence $(8 \%$ for $T$. serialis and $4 \%$ for $T$. pisiformis) seems to be influenced by the availability of their intermediate hosts as a trophic resource within the territory occupied by the wolves.

The ecological niches of most satellite species take up spaces unoccupied by core and secondary species. Alaria alata and Trichuris vulpis are located in distal areas of the intestine, the first and last sections respectively. This fact may be due to the interactions established with the other species of the community, and especially to the adaptive ability of $A$. alata and $T$. vulpis, since both helminth species show the same localisation in Spanish foxes (unpublished data). Similar findings have been observed in the case of the ascaridids, which leads us to hypothesize that the level of specialisation of these parasites is even higher with regard to the site than the host specificity. The apparent overlap found among the ecological niches of Toxocara canis (15.2-35.6\%) and Toxascaris leonina (20.4-32.1\%) was confirmed by the absence of statistically significant differences between their median distributions.

The results of the present study indicate that the structure of the intestinal helminth communities of $C$. lupus in Spain may be dominated by a small group of species that strongly affect the presence and intestinal distribution of all other species that are sporadically found parasitizing wolves. The component community of wolves shows several species ancestrally associated with the host, as well as others that have become part of its helminthfauna, probably by adaptive processes of the canid because of factors affecting its populations.

Acknowledgements. The authors wish to thank Luis Llaneza (ARENA Asesores en Recursos Naturales, S.L. Langreo, Asturias, Spain) for providing the viscera of most of the wolves examined in the present study, and Nygil Murell for 
improving the English text. This study was partially supported by the Comissionat per a Universitats i Recerca de la Gener- alitat de Catalunya (2001 SGR 00088) and by the Spanish DGICYT Project (BOS 2000-0570-C02-01).

\section{REFERENCES}

BALASINGAM E. 1964: Comparative studies on the effects of temperature on free-living stages of Placoconus lotoris, Dochmoides stenocephala and Ancylostoma caninum. Can. J. Zool. 42: 907-918.

BLANCO J.C., REIG S., CUESTA L. 1992: Distribution, status and conservation problems of the wolf, Canis lupus, in Spain. Biol. Conserv. 60: 73-80.

BURROWS R.B. 1962: Comparative morphology of Ancylostoma tubaeforme (Zeder, 1800) and Ancylostoma caninum (Ercolani, 1859). J. Parasitol. 48: 715-718.

BUSH A.O., HOLMES J.C. 1986a: Intestinal helminths of lesser scaup ducks: patterns of association. Can. J. Zool. 64: $132-141$.

BUSH A.O., HOLMES J.C. 1986b: Intestinal helminths of lesser scaup ducks: an interactive community. Can. J. Zool. 64: 142-152.

BUSH A.O., LAFFERTY K.D., LOTZ J.M., SHOSTAK A.W. 1997: Parasitology meets ecology on its own terms: Margolis et al. revisited. J. Parasitol. 83: 575-583.

CASWELL H. 1978: Predator-mediated coexistence: a nonequilibrium model. Am. Nat. 112: 127-154.

CUSTER J.W., PENCE D.B. 1981: Ecological analyses of helminth populations of wild canids from the Gulf Coastal Prairies of Texas and Louisiana. J. Parasitol. 67: 289-307.

FAGER E.W., McGOWAN J.A. 1963: Zooplankton species groups in the North Pacific. Science 140: 453-460.

FITZSIMMONS W.M. 1961: The so-called cat and dog strains of Ancylostoma caninum. Vet. Rec. 73: 585-586.

GIBBS H.C., GIBBS K.E. 1959: The effects of temperature on the development of the free-living stages of Dochmoides stenocephala (Ancylostomatidae: Nematoda). Can. J. Zool. 37: 247-257.

GUBERTI V., STANCAMPIANO L., FRANCISCI F. 1993: Intestinal helminth parasite community in wolves (Canis lupus) in Italy. Parassitologia 40: 80.

HANSKI I. 1982: Dynamics of regional distribution: the core and satellite species hypothesis. Oikos 38: 210-221.

HANSKI I. 1991: Core and satellite species - Theory and artifacts - Reply. Oikos 62: 88-89.

HOLMES J.C. 1973: Site selection by parasitic helminths: interspecific interactions, site segregation, and their importance to the development of helminth communities. Can. J. Zool. 51: 333-347.

HUTCHINSON G.E. 1957: Concluding remarks. Cold Spring Harbor Symp. Quant. Biol. 22: 415-427.
IANNACONE J.O., CORDOVA K.M., WONG R.V. 2001: Estructura comunitaria de helmintos de perros vagabundos de San Juan de Lurigancho, Lima, Perú. Rev. Bras. Zool. 18: $277-288$.

LOTZ J.M., FONT W.F. 1991: The role of positive and negative interspecific associations in the organization of communities of intestinal helminths of bats. Parasitology 103: $127-138$.

LOTZ J.M., FONT W.F. 1994: Excess positive associations in communities of intestinal helminths of bats: a refined null hypothesis and a test of the facilitation hypothesis. J. Parasitol. 80: 398-413.

MIQUEL J. 1993: Contribución al conocimiento de la helmintofauna de los carnívoros silvestres de Cataluña. Tesis Doctoral, Facultad de Farmacia, Universidad de Barcelona, 737 pp.

OKOSHI S., MURATA Y. 1967: Experimental studies on ancylostomiasis in cats. V. Visceral migration of Ancylostoma tubaeforme and Ancylostoma caninum in cats. Jpn. J. Vet. Sci. 29: 315-327.

OKOSHI S., MURATA Y. 1968: Experimental studies on ancylostomiasis in cats. VI. Visceral migration of larvae of Ancylostoma tubaeforme and Ancylostoma caninum in dogs. Jpn. J. Vet. Sci. 30: 43-51.

PENCE D.B., CRUM J.M., CONTI J.A. 1983: Ecological analyses of helminth populations in the black bear, Ursus americanus from North America. J. Parasitol. 69: 933950.

PENCE D.B., CRUM J.M., CONTI J.A., EASON S. 1980: Comparison of the helminth faunas of two sympatric top carnivores from the rolling plains of Texas. J. Parasitol. 66: $115-120$.

PENCE D.B., CRUM J.M., CONTI J.A., WINDBERG A. 1984: Population dynamics across selected habitat variables of the helminth community in coyotes, Canis latrans, from South Texas. J. Parasitol. 70: 735-746.

SCHLUTER D. 1984: A variance test for detecting species associations, with some example applications. Ecology 65: 998-1005.

SEGOVIA J.M., TORRES J., MIQUEL J., LLANEZA L., FELIU C. 2001: Helminths in the wolf, Canis lupus, from north-western Spain. J. Helminthol. 75: 1-11.

STORK N.E., LYAL C.H.C. 1993: Extinction or "coextinction" rates? Nature 366: 307. 